Background/introduction Reported sexual assaults have increased in England \& Wales since operation Yewtree. Sexual health services are ideally placed to manage and support victims of sexual assault. Clear patient pathways underpin the quality of care victims of sexual assault receive.

Aim(s)/objectives To assess our outcomes against the 2011 BASHH guidelines on the management of complainants of sexual assault.

Methods We undertook a case note review of all SA attendances to the CNC between August 2014 and July 2015

Results 114 sexual assault patients were seen, 87\% (99/114) were female, the median age was 23 years (13-66) and $96 \%$ (110/114) were white British or white other. 41\% (47/114) were referred by the Sexual Assault Referral Centre (SARC), 49\% (56/ 114) self-referred. $24 \%(27 / 114)$ reported being assaulted in an outside area, $16 \%(18 / 114)$ at a public venue and $20 \%(23 / 114)$ at the accused's home. 35\% (40/114) attended within 72 hours of the assault, 22\% (2/114) within 7 days, 17\% (19/114) within 2 weeks, 21\% (24/114) within 3 months and 4\% (5/114) within a year. 99\% (43/44) were appropriately assessed for PEPSE, $89 \%(64 / 72)$ were offered prophylactic antibiotics, 50/51 (99\%) of women were assessed for emergency contraception. 63\% (72/ 114) reported the assault to the police, $37 \%$ (9/28) who didn't report were offered third Party Reporting. STI infection rate was 6/114 (5\%).

Discussion/conclusion Our results suggest that our current management is in keeping with BASHH guidelines and that local referral pathways support patient care.

\section{P162 WHY ARE CORE MEDICAL TRAINEES NOT APPLYING FOR GENITOURINARY MEDICINE?}

\footnotetext{
${ }^{1}$ Nicolas Pinto-Sander*, ${ }^{1}$ Fionnuala Finnerty, ${ }^{1}$ Timothy Appleby, ${ }^{1}$ Deborah Williams, 1,2Daniel Richardson. 'Brighton and Sussex University Hospitals NHS Trust, Brighton, UK; ${ }^{2}$ Brighton \& Sussex Medical School, Brighton, UK
}

\subsection{6/sextrans-2016-052718.212}

Background/introduction Applications for higher speciality training in genitourinary medicine (GUM) have decreased dramatically in recent years leaving a number of unfilled posts. The reasons for this are unknown.

Methods We produced an anonymous electronic survey for CMTs which was distributed to all deaneries in the UK. Survey questions included the advantages/disadvantages of a career in GUM and main barriers to application. A specific question was asked regarding the impact that the Shape of Training review (SOT) would have on the perceived attractiveness of a career in GUM.

Results 100 CMTs responded, 51 CT1s and 49 CT2s. 35/100 were considering or applying for GUM and 17/100 may be. 61/ 100 gave reasons as to why they were not applying: 28\% (17/ $61)$ interested in another speciality, 33\% (20/61) no previous exposure, 21\% (13/61) no interest, 20\% (12/61) too specialist, and $3 \%(2 / 61)$ were uncertain of speciality future. The main advantage of GUM was an attractive work/life balance 44\% (32/ 73). When specifically asked about the SOT implementation and likelihood of applying for GUM, 94/100 responded. 27\% (25/ 94) were more likely to apply and for $36 \%$ (34/94) it made no difference. However of those applying/considering or maybe considering GUM ( $\mathrm{n}=52)$; 31\% (16/52) would be less likely to apply and $27 \%(14 / 52)$ would apply but not if SOT is implemented.
Discussion/conclusion This survey demonstrates that a significant proportion of CMTs are not considering GUM due to lack of exposure to the specialty. The SOT review is likely to significantly impact on GUM training, possibly deterring trainees currently considering applying but potentially also attracting other trainees who may not previously have considered it.

\section{P163 A QUALITATIVE EVALUATION OF THE PATIENTS KNOW BEST $^{\circledR}$ (PKB) PATIENT-CONTROLLED ELECTRONIC MEDICAL RECORD AND COMMUNICATION PLATFORM IN UK HIV SERVICES}

${ }^{1}$ Zoe Warwick*, ${ }^{2}$ Cicely Kerr, ${ }^{3,4}$ Beenish Nafees, ${ }^{3,4}$ Katy Gallop, ${ }^{4}$ Monica Hadi, ${ }^{2}$ Mitesh Desai, ${ }^{5}$ Mas Chaponda. 'Plymouth Hospitals NHS Trust, Plymouth, UK; ${ }^{2}$ JanssenCilag Ltd, High Wycombe, UK; ${ }^{3}$ Nafees Consulting Ltd, London, UK; ${ }^{4}$ Mapi Group, London, UK; ${ }^{5}$ Royal Liverpool and Broadgreen University Hospitals NHS Trust, Liverpool, UK

\subsection{6/sextrans-2016-052718.213}

Background/introduction Patients Know Best ${ }^{\circledR}$ (PKB) is an innovative, patient-controlled, medical record and communication platform aiming to facilitate patient centred care.

Aim(s)/objectives This qualitative service evaluation aimed to gain insight into the utility of PKB and experiences of users: specialist doctors, nurses and people living with HIV (PLWHIV).

Methods Participants were from 7 UK HIV centres that use PKB, 2 with PKB integrated with lab systems allowing automatic upload of blood results. Six doctors, 5 nurses and 4 PLWHIV took part in focus groups or individual interviews, which were audio-recorded and transcribed verbatim. Transcripts were systematically coded using a thematic analysis approach.

Results Participants had on average 1.5-2 years' experience of using PKB. PKB was mainly used to send/access lab results (automatically, or via secure messaging) or for other secure messaging e.g. clinicians uploaded clinic communications to GPs, care plans, letters for employment/sick notes, PLWHIV requested new/repeat prescriptions, booked appointments, queried results, symptoms and medication issues. Participants reported that PKB enabled different models of care (e.g. nurse-led, remote-monitoring) and use resulted in efficiencies and increased capacity, improved patient experience and self-management. Communication with GPs, pharmacists and clinicians in other departments via $\mathrm{PKB}$ was an area of unmet potential. Participants suggested lack of IT systems integration and resistance to PKB by some colleagues/PLWHIV were barriers to wider uptake.

Discussion/conclusion Varied benefits and value of PKB were reported. Overall experiences with $\mathrm{PKB}$ in UK HIV services were positive with all supporting continued use, greater uptake and integration.

\section{P164 MANAGEMENT OF PRIMARY AND SECONDARY SYPHILIS IN A LARGE LONDON TEACHING HOSPITAL}

Jo-Ann Mastin, Mary Tiab, Jake Bayley*. Barts Health NHS Trust, London, UK

\subsection{6/sextrans-2016-052718.214}

Background/introduction Acute syphilis is on the increase and prompt treatment is vitally important to prevent onward transmission.

Aim(s)/objectives To ensure compliance with BASHH audit outcomes for the management of acute syphilis.

Methods We collected all patients who had been coded as primary or secondary syphilis (A1 or A2) for 12 months from May 